\section{Revista Brasileira de Atividade Física e Saúde no ano de 2012: evoluções para contribuir com a remoção do "elefante na sala"}

\author{
Alex Antonio Florindo ${ }^{1}$ \\ Airton José Rombaldi ${ }^{1}$ \\ Mauro Virgílio Gomes de Barros ${ }^{1}$ \\ Thiago Terra Borges ${ }^{2}$
}

O ano de 2012 foi muito importante para a área de atividade física e saúde e para a Revista Brasileira de Atividade Física e Saúde (RBAFS). Com relação às evoluções na área, um dos fatos mais importantes foi à realização da quarta edição do Congresso Internacional de Atividade Física e Saúde Pública, realizado de 28 de outubro a 3 de novembro na cidade de Sydney, Austrália, onde o símbolo do "elefante" ficou famoso por estar em várias sessões do Congresso. O simbolismo do incômodo do "elefante na sala" foi uma ideia brilhante em sentido metafórico do Pesquisador Brasileiro Pedro Curi Hallal para expressar uma crítica à baixa atenção dada ao problema da inatividade física no mundo, em particular pelos administradores, políticos e editores de grandes revistas científicas relacionadas à saúde pública. Obviamente, tratou-se de uma crítica importante e que foi realizada com muito bom humor e era comum observar nas diversas salas do debate vários elefantes de pelúcia colocados principalmente pelo Pesquisador Adrian Bauman (Presidente do Congresso). Neste sentido, o Congresso de Sydney foi marcado por muitos debates sobre vários temas relacionados à atividade física e saúde com pesquisadores de vários países do mundo, mas as principais discussões foram sobre os esforços que vem sendo realizados para contribuir com o aumento dos níveis de atividade física da população. Durante o evento em Sydney, também foi anunciado oficialmente que a próxima edição do Congresso será realizada na cidade do Rio de Janeiro (Brasil), em maio de 2014.

Outro marco histórico ocorrido em 2012 foi o lançamento da série de atividade física e saúde pela Revista The Lancet, na sala Jeremy Morris da London School of Hygiene \& Tropical Medicine, pouco antes da XXX edição dos Jogos Olímpicos da era moderna da Cidade de Londres. A organização desta série foi liderada pelo Pesquisador brasileiro Pedro Curi Hallal, que foi Editor-Chefe da RBAFS até 2011 e que é o atual presidente da Sociedade Brasileira de Atividade Física e Saúde. $\mathrm{Na}$ série de artigos publicados na Lancet, os autores realizaram uma síntese do conhecimento disponível quanto a inter-relação atividade física e saúde, notadamente no tocante a prevalência e fatores associados à pratica de atividade física, às intervenções para a promoção da atividade física e o quanto o efeito da inatividade física contribui para um grupo importante de doenças crônicas que afetam a população mundial. A principal mensagem que a série de artigos procurou veicular foi a de que um dos legados mais importantes que os Jogos Olímpicos poderiam deixar seria a contribuição para estimular e oferecer condições para as pessoas praticarem atividade física.

Quanto à contribuição da RBAFS para remover o "elefante da sala”, nós conseguimos evoluir para seis números por ano em comparação com os quatro núme-
Rev Bras Ativ Fis Saúde p. 461-462 DOI: http://dx.doi.org/10.12820/23171634.2012v17n6p461

1 Editores-Chefes da revista Brasileira de Atividade Física e Saúde

2 Editor Assistente da Revista Brasileira de Atividade Física e Saúde 
ros de 2011. Em 2012 foram publicados 60 artigos originais, cinco artigos de revisão sistemática, quatro artigos descrevendo programas de promoção da atividade física e cinco artigos de divulgação de programas de pós-graduação relacionados à atividade física e saúde. Pensando na internacionalização da revista foi implantada a tradução opcional de artigos científicos por tradutores especializados, sendo que 12 artigos foram publicados também em inglês. A RBAFS foi implantada na plataforma eletrônica SEER <http://periodicos.ufpel.edu.br/ojs2/index.php/RBAFS> e foi atribuído um novo ISSN para a versão eletrônica da revista. A RBAFS se tornou membro da CrossRef e passou a atribuir registros DOI para todos os seus artigos publicados a partir do número 5 de 2012. Chegamos ao final de ano de 2012 com todas as nossas metas plenamente alcançadas e todas contribuirão para o principal objetivo de 2013: indexar a RBAFS na plataforma Scielo. Gostaríamos de agradecer a todos os nossos revisores e aos nossos editores associados, Professores Claudia Lúcia Forjaz, Julia Nogueira, Raphael Mendes Ritti, José Cazuza de Farias Júnior, Felipe Fossati Reichert e Rodrigo Siqueira Reis por todo o trabalho em prol da RBAFS no ano de 2012, pois sem a dedicação deles nós não teríamos alcançado todas as metas estipuladas. Cada pequena conquista e cada pequeno avanço representou em certa medida a contribuição e o esforço de cada um de seus autores, revisores, editores associados, editores assistentes, editores-chefes e de toda comunidade da área de atividade física e saúde para o árduo trabalho de se remover o "elefante da sala". Vamos em frente contribuindo para promover a prática de atividade física e para melhorar a saúde pública. 